NBER WORKING PAPER SERIES

\title{
LABOR FORCE PARTICIPATION OF THE ELDERLY IN JAPAN
}

\author{
Takashi Oshio \\ Emiko Usui \\ Satoshi Shimizutani \\ Working Paper 24614 \\ http://www.nber.org/papers/w24614
NATIONAL BUREAU OF ECONOMIC RESEARCH
1050 Massachusetts Avenue
Cambridge, MA 02138
May 2018

The views expressed herein are those of the authors and do not necessarily reflect the views of the National Bureau of Economic Research.

NBER working papers are circulated for discussion and comment purposes. They have not been peer-reviewed or been subject to the review by the NBER Board of Directors that accompanies official NBER publications.

(C) 2018 by Takashi Oshio, Emiko Usui, and Satoshi Shimizutani. All rights reserved. Short sections of text, not to exceed two paragraphs, may be quoted without explicit permission provided that full credit, including ( $)$ notice, is given to the source. 
Labor Force Participation of the Elderly in Japan

Takashi Oshio, Emiko Usui, and Satoshi Shimizutani

NBER Working Paper No. 24614

May 2018

JEL No. H55,J21,J26

\begin{abstract}
$\underline{\text { ABSTRACT }}$
Japan experienced increases in labor force participation (LFP) of the elderly in recent years, as have other advanced countries. In the present study, we overview the employment trend of the elderly in Japan, and examine what factors have contributed to its increase since the early 2000s. Improved health and longevity, increasing education levels, and a shift towards less physically demanding jobs have allowed the elderly to stay longer in the labor force. However, elderly employment rebound and its timing are more closely linked to changes in social security incentives, especially increases in the eligibility age for public pension benefits. More broadly, reduced generosity in social security programs since the mid-1980s has been a key driver of the long-term trend change in elderly employment. A series of social security reforms have helped utilize the elderly's potential work capacity, accumulated due to improving health conditions and other favorable factors for LFP in the elderly.

Takashi Oshio

Institute of Economic Research

Hitotsubashi University

2-1 Naka, Kunitachi

Tokyo 186-8603 Japan

oshio@ier.hit-u.ac.jp

Emiko Usui

Institute of Economic Research

Hitotsubashi University

2-1 Naka, Kunitachi

Tokyo 186-8603 Japan

usui@ier.hit-u.ac.jp

Satoshi Shimizutani

Institute for International Policy Studies

5th floor, Toranomon 5 Mori Building,

1-17-1 Toranomon, Minato-ku

Tokyo 105-0001 Japan

sshimizutani@gmail.com
\end{abstract}




\section{Introduction}

Aging population has an adverse impact on fiscal positions of social security programs and long-term growth potential, encouraging labor force participation (LFP), needed to mitigate demographic pressures. Moreover, social security benefits have been reducing the elderly’s incentives to work (Gruber and Wise, 1997). As such, previous studies have demonstrated that social security programs’ enhanced generosity has been reducing elderly’s labor supply, despite general improvement in their health condition (Usui, Shimizutani, and Oshio, 2016; Wise, 2017). At the same time, transition from work to retirement has become more complicated and diversified among the elderly, via disability and unemployment insurance programs, as well as core public pension schemes (Wise, 2012; Wise, 2015).

An association between social security benefits and elderly work/retirement decisions has been observed in Japan, although the elderly LFP rate is much higher than in other advanced countries (Yashiro and Oshio, 1999). Additionally, the elderly LFP had been on a downtrend since the 1960s, and amplified by a long-term decline in the proportion of self-employed workers and farmers. Furthermore, compared to other countries, disability insurance programs play a limited role as transition from work to retirement (Shimizutani, Oshio, and Fujii, 2015).

However, in the last two decades, there has been a remarkable change in the elderly's labor market in Japan. The elderly's LFP and, more specifically, employment have been on an uptrend after a stabilizing period in the early 2000s. Several factors have contributed to these changes, including changes in incentives related to social security and disability insurance programs, improved health and longevity, increased educational attainment, a shift towards less physically demanding jobs, and rising female LFP (combined with the desire for joint retirement among couples). Their relative importance is likely to differ substantially across countries, and some of them may be less relevant to Japan. 
In this study, we overview the recent trend of elderly's LFP in Japan and discuss what factors have contributed to its rebound. We focus on employment, considering that the unemployment rate among the elderly has been relatively low and stable in Japan. Our findings highlight the role played by public social security programs changes as key determinants of the variation in the elderly's employment long-term trend.

The remainder of the paper is organized as follows: section 2 provides an overview of recent trends in elderly employment, with specific reference to social security programs; section 3 discusses factors that could have contributed to the recent increases in elderly employment; section 4 focuses on social security incentives and their impact on elderly employment long-term evolution, based on the results of Oshio, Oishi, and Shimizutani (2011); and section 5 concludes the paper.

\section{Recent trends in elderly employment and social security programs}

\subsection{Employment patterns of elderly men}

The overview of the elderly's employment recent trends is using aggregated data from Labor Force Surveys released by of the Ministry of Internal Affairs and Communications. Figure 1 depicts recent fluctuations of male employment rates, dividing them into four age groups (aged 55-59, 60-64, 65-69, and 65+). The data of those aged 65-69 are available only from 2002.

The employment rate of those aged 55-59 has been staying high at around 90\%, despite cyclical fluctuations, because their ages are lower than the mandatory retirement and pensionable ages. Meanwhile, the employment rate of those aged 60-64 bottomed in the early 2000s but has been rising since. This age group has been dominating the dynamics of elderly' employment, with the timing of the rebound after the late 1990s, as observed in other advanced 
countries. The employment rate of those aged 65-69 has also been on an uptrend since the mid-2000s, albeit more modest than for the 60-64 age group. This movement presumably reflected the cohort effect: those more active at age 60-64 were more inclined to stay in workforce at age 65-69. Moreover, the employment rate of those aged 65+ has stopped declining in the mid-2000s, probably led by a rise in that of those aged 65-69.

Consequently, employment of elderly males stabilized in the early 2000s and has been on an increasing trend since. This evolution has been largely led by those aged 60-64, an age group that is usually in transition from work to retirement and, thus, most likely affected by the overall economic conditions and social security programs. As younger age groups tend to be close to full employment and older ones are more likely to have retired, both have limited impact on the changes of elderly employment.

Nonetheless, turnaround of the 60-64 age group's LFP is not fully attributable to a change in macroeconomic conditions. Figure 2 compares the employment rate of this male age group with the national male unemployment rate (on a reverse scale). As seen in this figure, the elderly's employment rate had been moving with the nationwide unemployment rate until the late 1990s. However, in the early 2000s the gap between two variables started to widen, deviating from their previous co-movement. The elderly have been raising their labor supply since then, despite an increase in nationwide unemployment due to the overall economic downturn. Additionally, this figure suggests that institutional changes affected the elderly's labor market in the early 2000s, and that tighter national labor market conditions around 1990 accounted for a delayed trough of elderly employment compared to other countries (see Figure xx in Chapter xx).

A plausible factor for the elderly employment rebound in the early 2000s was an increase in the eligibility age of the Employees’ Pension Insurance (EPI), a public pension program for employees in the private sector. The EPI benefits consist of a flat-rate component (basic 
pension) and a wage-proportional one. The eligibility age for male EPI members was 60 for both components, but the flat-rate one was raised by one year every three years starting in 2001, and going up to 65 by 2013. The eligibility age of the wage-proportional benefit is raised by one year every three years since 2013 and is scheduled to increase to 65 by 2025. Figure 3 compares the evolution of the eligibility age for EPI benefits and employment rate of males aged 60-64, and shows that both a rise in the employment rate and the timing of its start were closely associated with a rise in eligibility age for the flat-rate benefit from age 60 .

Along with an increase in the eligibility age of EPI benefits, a series of policy measures to stimulate the elderly LFP were implemented. First, the Continuous Employment Benefits for the Elderly was introduced in 1995 to subsidize 15\% of the pre-retirement wage for those aged 6064 who kept working after mandatory retirement. Second, the disincentive effects of the Zaishoku pension benefits (i.e., income-tested EPI benefits for active employees) were reduced in 2005. Finally, the Law for the Stabilization of Employment of the Aged was enforced in 2000, 2004, and 2012 to recommended/required firms to keep employing workers until at least 65. These policy measures allowed EPI members to postpone retirement, resulting in an increase in the employment rate of the 60-64 age group since the early 2000s.

\subsection{Employment pattern of elderly women}

The elderly female employment also has been increasing in recent years, although there are some differences from the case of males. As such, Figure 4 depicts female employment rate, dividing them into four age groups (aged 55-59, 60-64, 65-69, and 65+). Unlike males, the rate of employment for the 55-59 age group started rising in the late 1980s, and, after a short pause, it resumed rising. Meanwhile, the employment rate of the 60-64 age group remained almost constant, at a level slightly lower than $40 \%$ until the mid-2000s, and subsequently started rising 
abruptly, somewhat later than for males. The trend for the 65-69 and 65+ age groups are similar to those for males.

Additionally, the dynamics of female employment rates are closely related to rises in the eligibility age of EPI benefits. Figures 5a and 5b compare the evolutions of the EPI eligibility age with the employment rates of females aged 55-59 and 60-64, respectively. However, the EPI eligibility age differs between men and women. Unlike for males, the eligibility age for the flat-rate and wage-proportional benefits, both of which used to be set at 55 , five years younger than for males, had been raised by one year every three years from 55 in 1987 to 60 in 1999. The eligibility age of the flat-rate benefit resumed rising in 2006, five years later than for males.

An increase in female employment of the 55-59 age groups during the late 1980s and 1990s (not observed for males) was consistent with the adjustments of the EPI eligibility age (Figure 5a). For those aged 60-64, the employment rate started increasing in the mid-2000s, after a modest increase compared to the previous decades (Figure 5b). This change was consistent with a rise in the eligibility age of the EPI flat-rate benefit starting in 2006, which has also encouraged those aged 55-59 to stay longer in labor force, since the employment rate for those aged 55-59 resumed rising in the mid-2000s.

\section{Determinants of elderly employment increase}

\subsection{Employed and self-employed workers}

The previous section overviewed the recent increase in elderly employment, with specific reference to the increases in the eligibility age for EPI benefits. This section discusses other factors that may have favorably affected the elderly LFP, such as a decrease in self-employed workers, an increase in part-time workers, higher education, more jobs that require less physical 
exertion, and improving health conditions.

As such, we focus on different trends of employed and self-employed workers (including farmers). A reduction in self-employed workers has led to a long-term downtrend of elderly employment, meaning that the recent rebound was driven by an increase in employed workers. In addition, the work/retirement decisions of self-employed workers are not likely to have been affected, at least directly, by recent social security reforms, as they are covered by the National Pension Insurance (NPI), which has only the flat-rate benefit and a fixed the eligibility age of 65 since 1960, although the amount of the benefit has changed.

To capture the different trends of employment between employed and self-employed workers, Figure 6 decomposes workers aged 60-64 into these two groups and compares their contributions to changes in employment rate since 1985, for both males and females. The data are based on the Population Census released by the Ministry of Internal Affairs and Communications.

For males, we observe that the proportion of self-employed workers to the total population aged 60-64 declined steadily from 31.4\% in 1985 to $17.1 \%$ in 2010, and contributed negatively to the overall employment rate of this age group. In addition, there are no changes in the curve for this group, which is consistent with no change in the eligibility age for NPI benefits. In contrast, the proportion of employed workers increased, with a short period of reduction in 1995-2000). An increasing number of employees aged 60-64, who used to retire, are now continuing to work. This increase has been offsetting a reduction in the proportion of self-employed workers, leading to a U-shaped rebound of the employment rate for this age group. The short period of reduction corresponds to a post-boom reduction in the elderly labor demand.

We observe a similar development for females: an increase in employed workers has been 
offsetting a decrease in self-employed workers. However, unlike males, females’ overall employment rate has not been falling since 1985, and the increase in employed workers has been smoother than for males, probably reflecting the lack of changes in the EPI eligibility age for this age group (until 2013).

\subsection{Full- and part-time employees}

The previous subsection confirms that the recent increase in elderly employment accounted for an increase in employees rather than self-employed individuals. Subsequently, we divide employed workers into full- and part-time. Based on the data from the Labor Force Survey, Figure 7 compares the proportion of part-time workers in total employees between the 55-64 and 65+ age groups for males and females.

For males aged $60-64$, the proportion of part-time employees has remained low between 1990 and 2015, although it has been gradually rising. This suggests that an increase in employment for those aged 60—64 has reflected postponed retirement of full-time employees who responded to the raised eligibility age of EPI benefits. For those aged 65+, the proportion of part-time employees has been rising more, suggesting that those who have retired from their jobs and/or started to claim EPI benefits were inclined to stay in the labor force as part-time workers.

For females, the proportion of part-time employees has been much higher than for males for both age groups. The proportion has been increasing over recent decades for both 55-64 and 65+ age groups, indicating that the recent increase in elderly female employment has been concentrated on part-time.

\subsection{Higher education and less physical constraints}


There are two structural changes in the elderly labor market, which have probably contributed to their employment in recent decades, that is, an increasing proportion of highly educated workers and a decreasing proportion of blue-collar workers (Figure 8). Combined with the health conditions improvement, these two factors have allowed employees to stay longer in the labor force.

Moreover, the proportion of those who graduated from college or above has been rising remarkably. According to the Wage Census of the Ministry of Health, Labour and Welfare, the proportion of college (including graduate school) employees aged 55-64 rose from 6.7\% to 32.5\% for males and from $0.9 \%$ to 9.0\% for females between 1975 and 2014. Meanwhile, the proportion of blue-collar workers declined from $34.2 \%$ to $19.5 \%$ for males and from $37.1 \%$ to $16.6 \%$ for females during the same period, along with a shift from the manufacturing to the service sector.

\subsection{Improving health conditions}

Another important factor for elderly employment is the health and longevity improvement. To confirm this, we looked at two health variables, that is, life expectancy and mortality rates at age 60, over the last two decades (Figure 9), based on the data from the Life Tables released by the Ministry of Health, Labour and Welfare. Life expectancy at age 60 has been increasing from 15.9 to 23.4 years for males and from 19.3 to 28.7 years for females between 1970 and 2014 . Consistently, the mortality rate at age 60 has been declining from 0.0173 to 0.0070 for males and from 0.0099 to 0.032 for females during the same period.

The two measures confirm substantial improvement in elderly's health conditions, which would allow them to remain active and work longer. However, the elderly males have been reducing LFP over time in response to wider coverage of social security programs and 
increasing benefits (Yashiro and Oshio, 1999). Consequently, the employment rate of elderly males has been positively correlated with their mortality rate, both variables declining simultaneously. This fact suggests that, first, improving health conditions have not led a rebound in elderly male employment, even if they may have prevented it from declining further. Second, substantial work capacity remains unutilized among elderly males, meaning that social security reforms can potentially enhance elderly employment (Usui, Shimizutani, and Oshio, 2016).

However, the relationship between elderly employment and health has remarkably changed since the early 2000s, and differs substantially between males and females. Figure 10 shows the combinations of the mortality rate at age 60 and the employment rate of those aged 60-64 for males and females between 1970 and 2014.

For males, both mortality and employment declined until around 2000, resulting in their positive correlation. Around 2000, the curve of their combinations turned up and left, that is, the employment rate rebounded, while the mortality rate continued to decline. A series of social security reforms and related policy measures, in particular, an increase in the eligibility age of EPI benefits, made the elderly males stay longer in the labor force, deviating from the previous, negative correlation between health and employment. In other words, a series of policy reforms made it possible to realize the potential working capacity, which had been created by improved health conditions.

The observed relationship between health and employment changed remarkably in the mid-2000s for elderly females as well. Until then the curve had been nearly flat, indicating that employment had been nearly constant, as observed in Figures 4 and 6b, despite improved health conditions. In the mid-2000s, the curve turned up and left, which roughly corresponded to an increase in elderly female employment in response to a rise in the eligibility age for EPI benefits starting in 2006. As for males, social security reforms helped utilize the elderly’s work capacity, 
due to improved health and longevity.

\section{Social security incentives and elderly employment}

\subsection{Social security incentives and option values}

As discussed in the previous sections, an increase in the eligibility age for EPI benefits seems to have been closely related to the rebound of elderly employment. However, recent social security reforms, which have been launched almost every five years since 1954, have incorporated other measures as well. Notably, social security reforms from 1985 and after have been reducing the overall generosity of benefits, in particular, by reducing the benefit multiplier of wage-proportional benefits, in contrast to the previous reforms that aimed to raise it. This section evaluates the impact of these reforms in terms of the option value (OV), as per Oshio, Oishi, and Shimizutani (2011).

The OV model assumes that an individual compares utility today with that at the optimal future retirement age and chooses the optimal retirement age as such. The indirect utility function over work and leisure of an individual aged $t, V_{t}(r)$, is expressed as

$$
V_{t}(r) \equiv \sum_{s=a}^{r-1} p_{s \mid t} d^{s-t}\left(y_{s}\right)^{g}+\sum_{s=r}^{D} p_{s \mid t} d^{s-t}\left[k B_{s}(r)\right]^{g}, 0<g<1, k \geq 1,
$$

assuming that he/she will retire at age $r(\geq t) . B_{s}(r)$ is the benefit that an individual is expected to receive at age $s(\geq r), d$ is the cumulative discount rate, $p_{s \mid t}$ is the probability of being alive at age $s$ (conditional on being alive at age $t$ ), $D$ is the maximum age, $y$ is the wage income while working, $g$ is a parameter of risk aversion, and $k$ is a parameter that accounts for the disutility of labor $(k \geq 1) . B_{s}(r)$ usually tends to rise as $r$ increases, reflecting a longer period of premium contributions, and is equal to 0 if $s$ is below the eligibility age.

The optimal retirement age maximizes indirect utility, that is, the age at which the utility 
gain derived from the additional work wage increase begins to be outweighed by the utility loss from retirement income decrease. As such, OV is defined as the difference between indirect utility from retirement at optimal age $r^{*}$ and indirect utility from retiring today and can be expressed as

$$
O V_{t}(r) \equiv V_{t}\left(r^{*}\right)-V_{t}(r) .
$$

To compute OV, the values of $k$ and $g$ are required. Using data obtained from the Labor Force Survey, we search for the combination of $k$ and $g$ that maximizes the goodness of fit of the model, which regresses LFP on OV. We find that the combination of $k=2.0$ and $g=0.75$, and that of $k=3.0$ and $g=0.75$ are most appropriate for males and females, respectively. Consequently, we adopt the typical person approach developed by Engelhardt and Gruber (2004); that is, we apply the same earnings profile to all cohorts and construct incentive measures according to the available social security programs. Specifically, we use the 1935 birth cohort as a benchmark, and assign its earnings profile to every subsequent cohort. Based on this earnings profile, we calculate OV under the existing annual social security program. Finally, we calculate its annual weighted average by gender.

In addition, we conduct counter-historical simulations to estimate how social security reforms have affected the elderly's labor supply since 1985 . We examine what OV would have looked like if the government had not implemented major social security reforms. For example, to estimate the impact of the 1985 and subsequent reforms, we construct all the parameters in the social security programs, including the benefit multiplier, premium rates, and eligibility ages fixed in 1984, and generate the paths OV would have taken since 1985 without any reform. In the same manner, we can construct the paths without reforms since the 1989 reform, and roughly interpret the difference between these simulated paths as the impact of the 1985 reform. The experiments can be repeated to capture the impact of each reform. 


\subsection{Assessing the changing generosity of social security programs}

Figures 11a and 11b depict the estimated evolution of the weighted average of OV for those aged 55-69, to capture the changing overall generosity of social security programs for males and females, respectively. For both males and females, the U-shaped OV curves bottomed around 1995 for males and 1990 for females. This is consistent with social security programs starting to reduce generosity in the 1985 reform, considering a transition period.

A turnaround in the generosity, which is reflected in the U-shaped OV curves, led to a turnaround of elderly employment. As seen in Figures 1 and 4, the tighter labor market conditions in the aftermath of the economic expansion of the late 1980s obscured the relationship between the OV and elderly employment. In addition, the rise in elderly employment rates were triggered by increases in the eligibility age for EPI benefits. However, a series of social security reforms starting in 1985 have been accumulating the momentum of enhancing elderly work incentives by a reduction in the overall generosity of social security programs.

Figures 11a and 11b also present the results of these counter-historical simulations on OV to assess the impact of social security reforms since 1985. For males (Figure 11a), the curve labeled "Without reform since 1985" depicts the path OV would have taken if the social security reform stopped just before the 1985 reform. In this case, OV for males would have declined further and would have leveled off in the late 1990s, as all the cohorts would have adopted the scheme that was applied just before the 1985 reform. The series of reforms since 1985 shifted the OV curve downward; however, the impact of the 1985 reform had been larger than that of any other reform.

The impact of social security reforms is also observed in the case of females (Figure 11b). 
The impact differs from that for males in that the 1985 reform raised the generosity of the programs for females until the mid-1990s, judging by the comparisons between the actual OV curve and the "Without reform since 1985" one. The 1985 reform called for a gradual increase in the eligibility age for females from 55 to 60 , raising net benefits due to a prolonged period of premium contributions, which was much shorter than for males. Nevertheless, the figure confirms that the generosity of social security programs has been gradually decreasing since the late 1980s as for males.

Oshio, Oishi, and Shimizutani (2011) estimated the impact of social security reforms on the elderly's LFP, based on the counter-historical simulations of OV. They reported that social security reforms since 1985 increased the male and female labor force by $0.7-1.9 \%$ and $0.6-$ 0.9\% per year, respectively, between 1995 and 2007.

\section{Concluding remarks}

As most advanced countries, Japan has experienced increases in elderly’s labor force participation in recent years. In this study, we overviewed the recent trend of elderly employment, and examined what factors have contributed to its rebound since the early 2000s. Improved health and longevity, increased education levels, and a shift towards less physically demanding jobs seem to have allowed the elderly to stay longer in the labor force.

However, the rebound and its timing on elderly employment have been more closely linked to changes in social security incentives, especially the increases in the eligibility age for public pension benefits. The reduced generosity in social security programs since the mid-1980 has been a key driver of the recent increase in elderly employment and a series of social security reforms have helped utilize the elderly's potential work capacity, owing to improving health conditions and other favorable factors for the elderly's LFP. 


\section{REFERENCES}

Engelhardt, G. V. and J. Gruber (2004), “Social Security and the Evolution of Elderly Poverty,” NBER Working Paper, No. 10466.

Gruber, J. and D. A. Wise (eds.) (1999), Social Security and Retirement around the World, The University of Chicago Press.

Oshio, T., A. S. Oishi, and S. Shimizutani (2011), “Social security reforms and labor force participation of the elderly in Japan,” Japanese Economic Review, 62(2), pp. 248-271.

Shimizutani, S., T. Oshio, and M. Fujii (2015), “Option value of work, health status, and retirement decisions in Japan: Evidence from the Japanese Study on Aging and retirement (JSTAR),” in D. A. Wise (ed.), Social Security Programs and Retirement around the World: Disability Insurance Programs and Retirement, pp. 497-535.

Usui, E., S. Shimizutani, and T. Oshio (2016), "Health capacity to work at older age: evidence from Japan,” NBER Working Paper, No. w21971.

Wise, D. A. ed. (2012), Social Security Programs and Retirement around the World: Historical Trends in Mortality and Health, Employment, and Disability Insurance Participation and Reforms, The University of Chicago Press.

Wise, D. A. (ed.) (2015), Social Security Programs and Retirement around the World: Disability Insurance Programs and Retirement, The University of Chicago Press.

Wise, D.A. (ed.) (2017), Social Security Programs and Retirement around the World: ..., The University of Chicago Press, forthcoming.

Yashiro, N. and T. Oshio (1999), “Social security and retirement in Japan,” in J. Gruber and D. Wise (eds.), Social Security and Retirement around the World, by J. Gruber and D. Wise, The University of Chicago Press, pp. 239-267. 
Figure 1. Employment rate: males

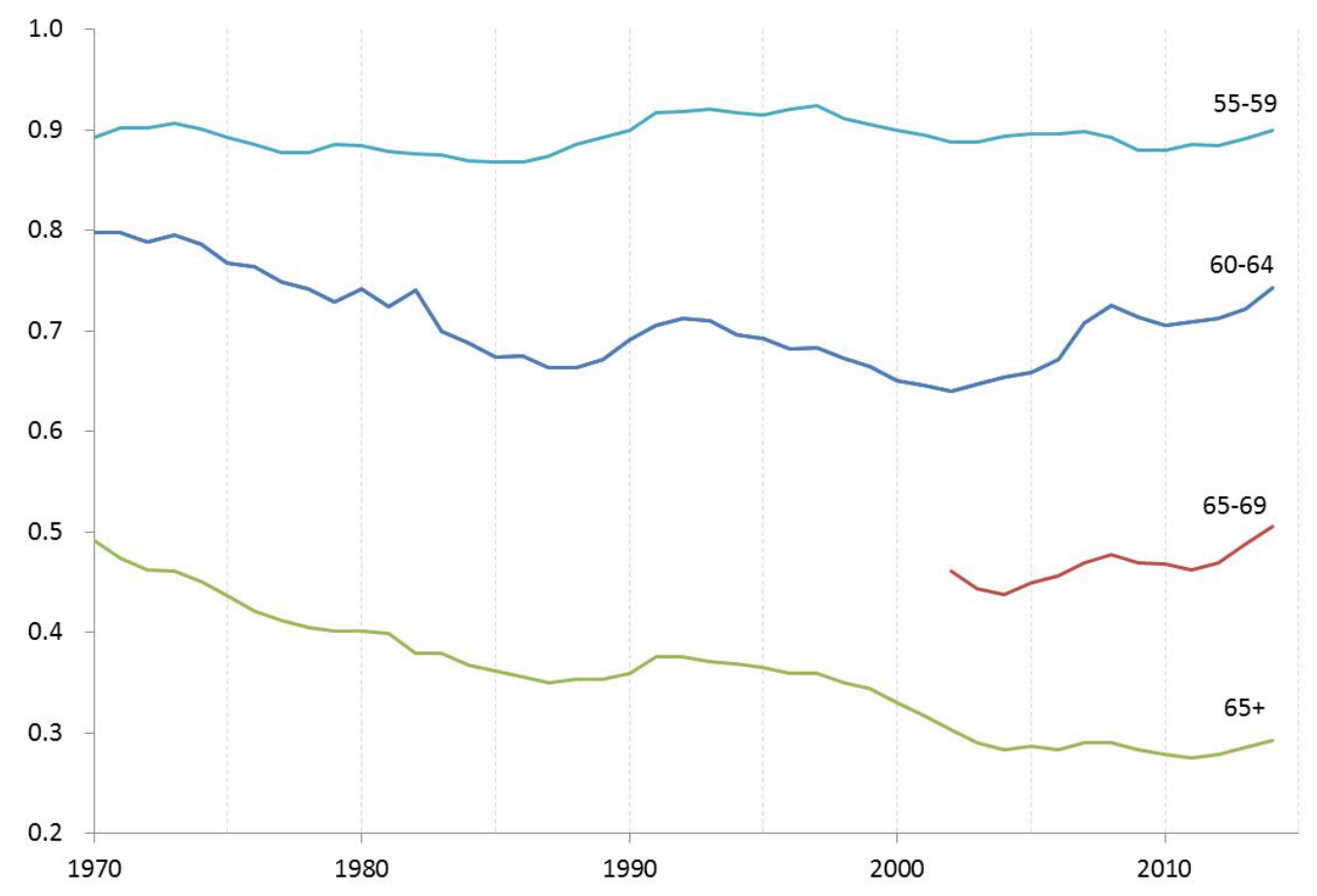

Figure 2. Unemployment rate for males aged 60-64 and at the national level

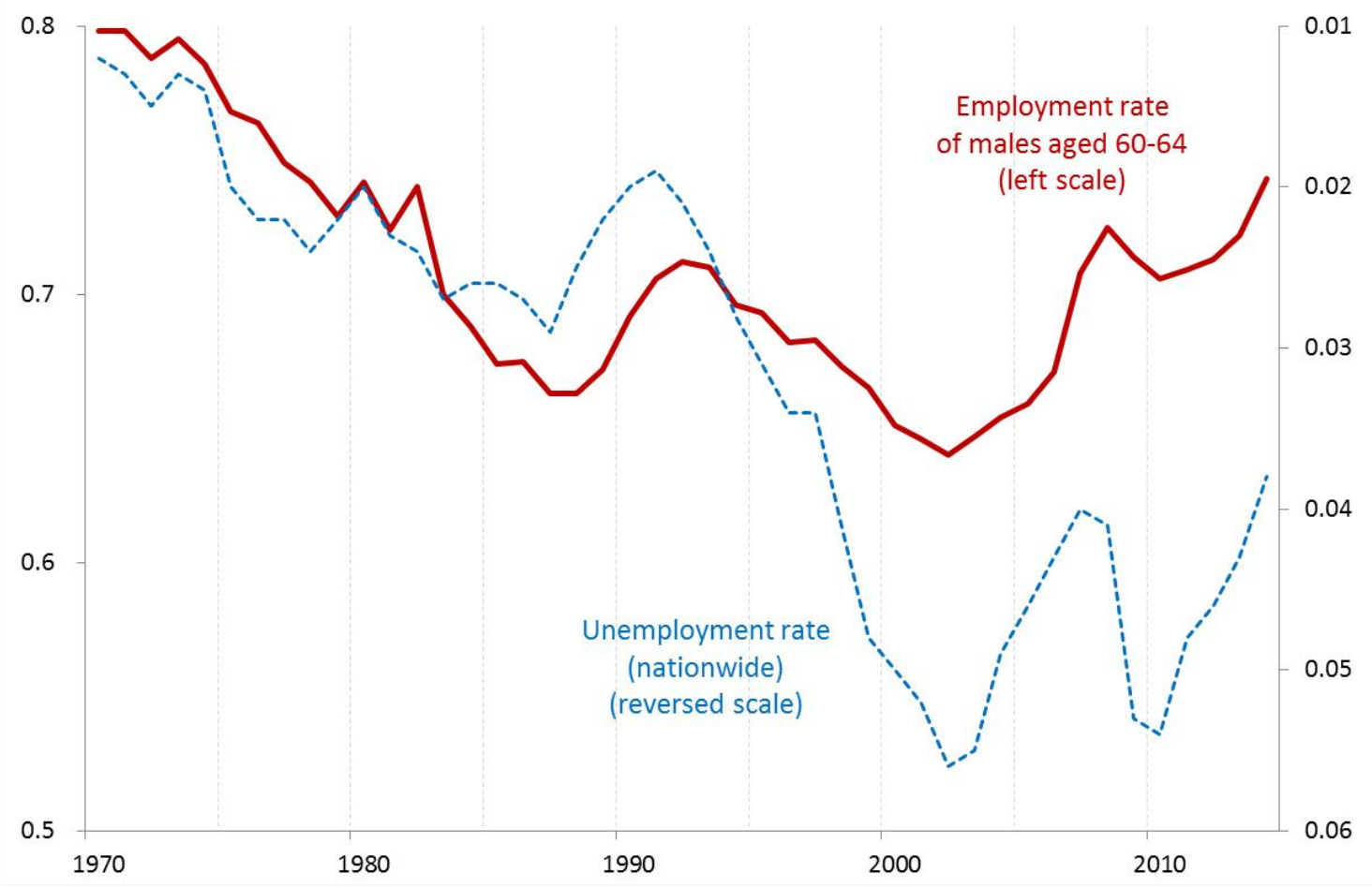


Figure 3. Employment of males aged 60-64 and eligibility age for EPI benefits

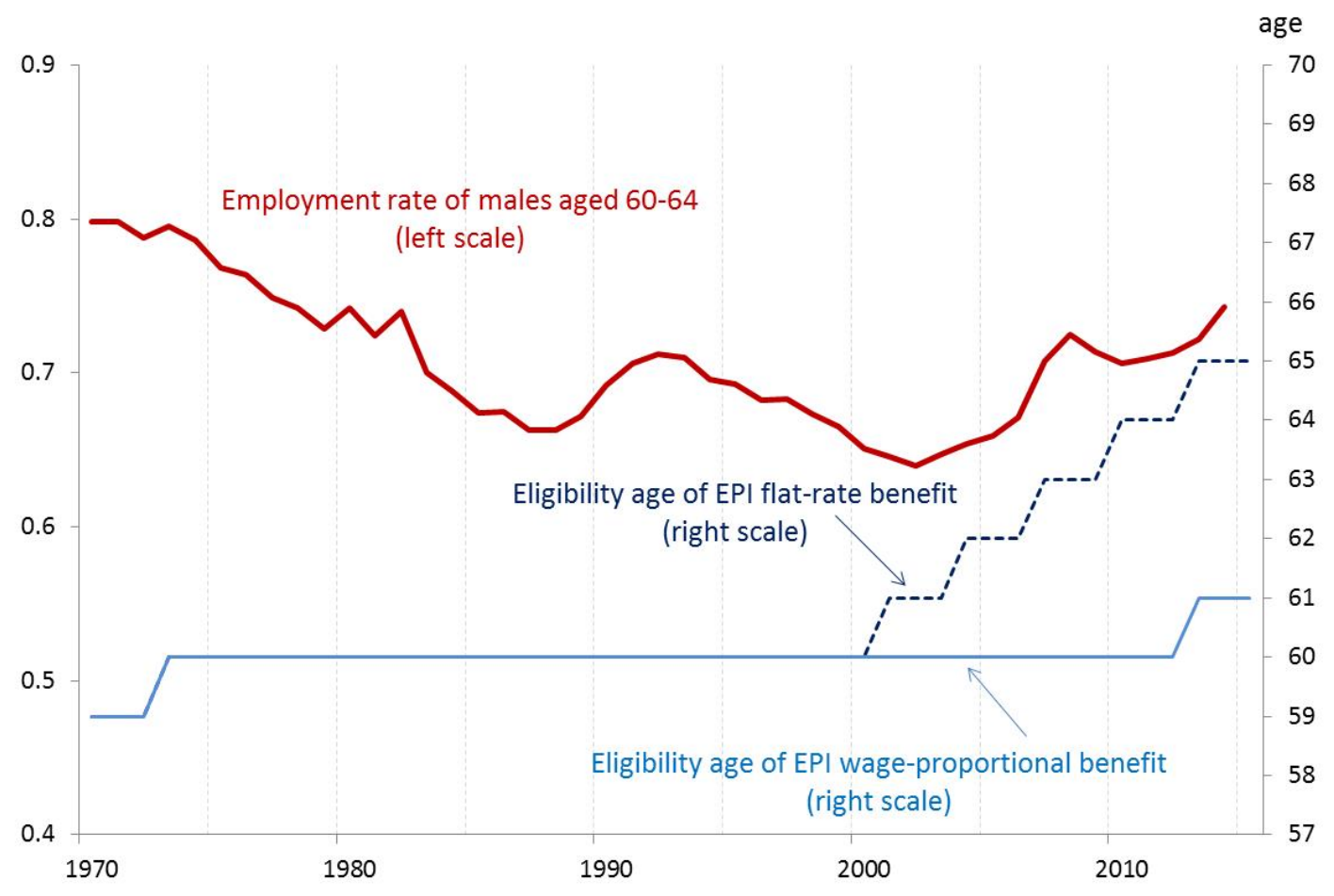

Figure 4. Employment rate: females

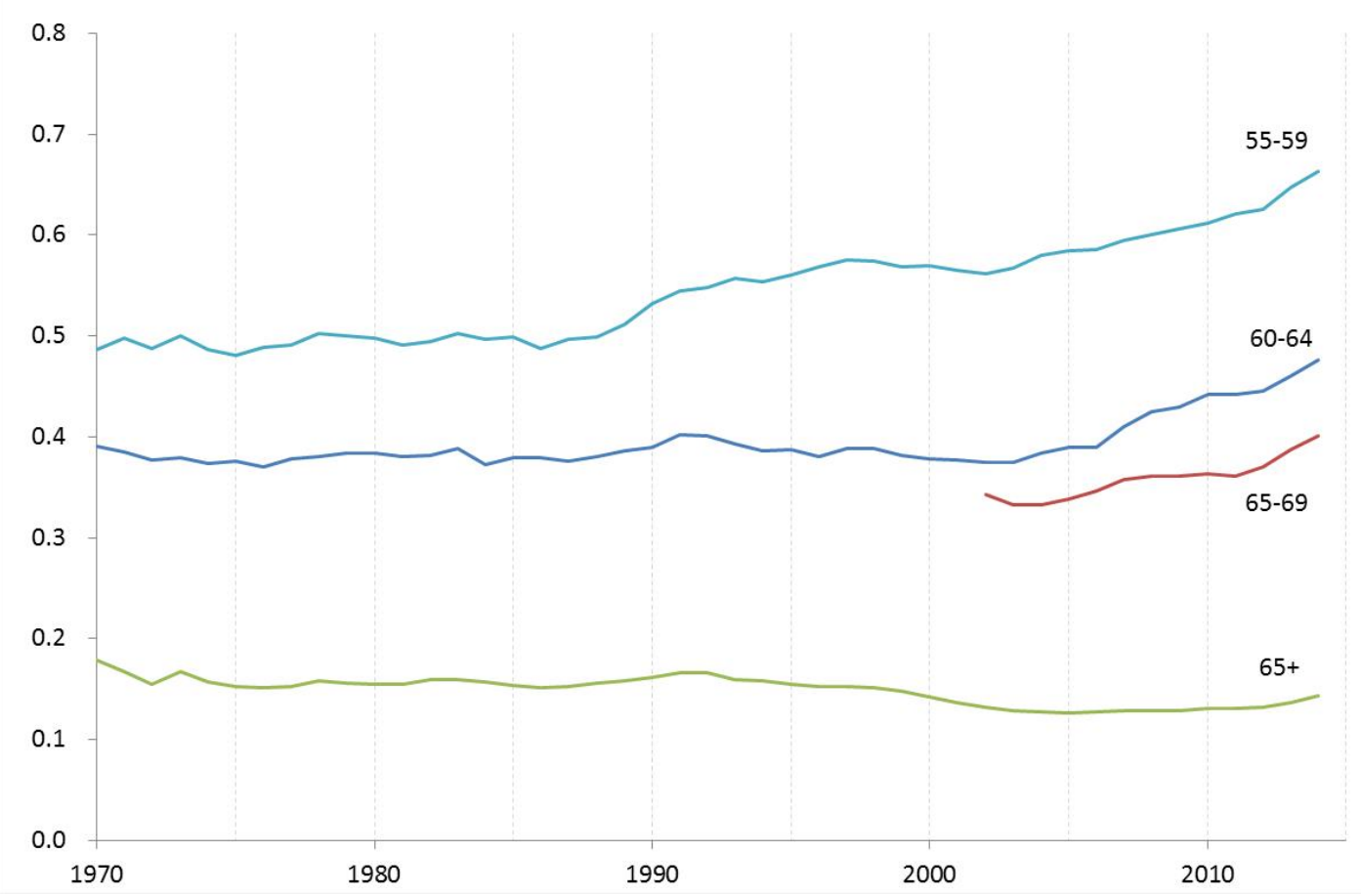


Figure 5a. Employment of females aged 55-59 and eligibility age for EPI benefits

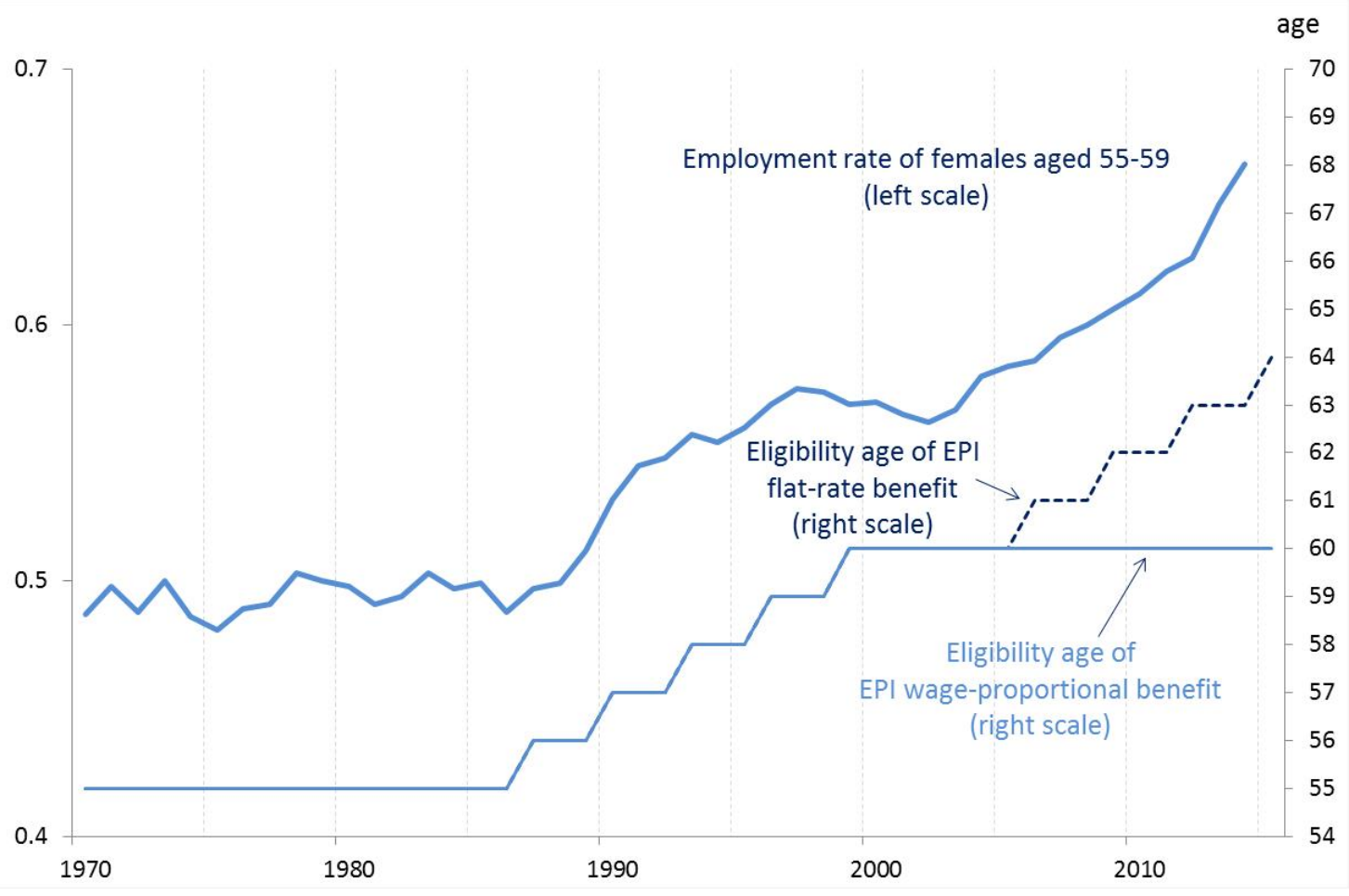

Figure 5b. Employment of females aged $60-64$ and eligibility age for EPI benefits

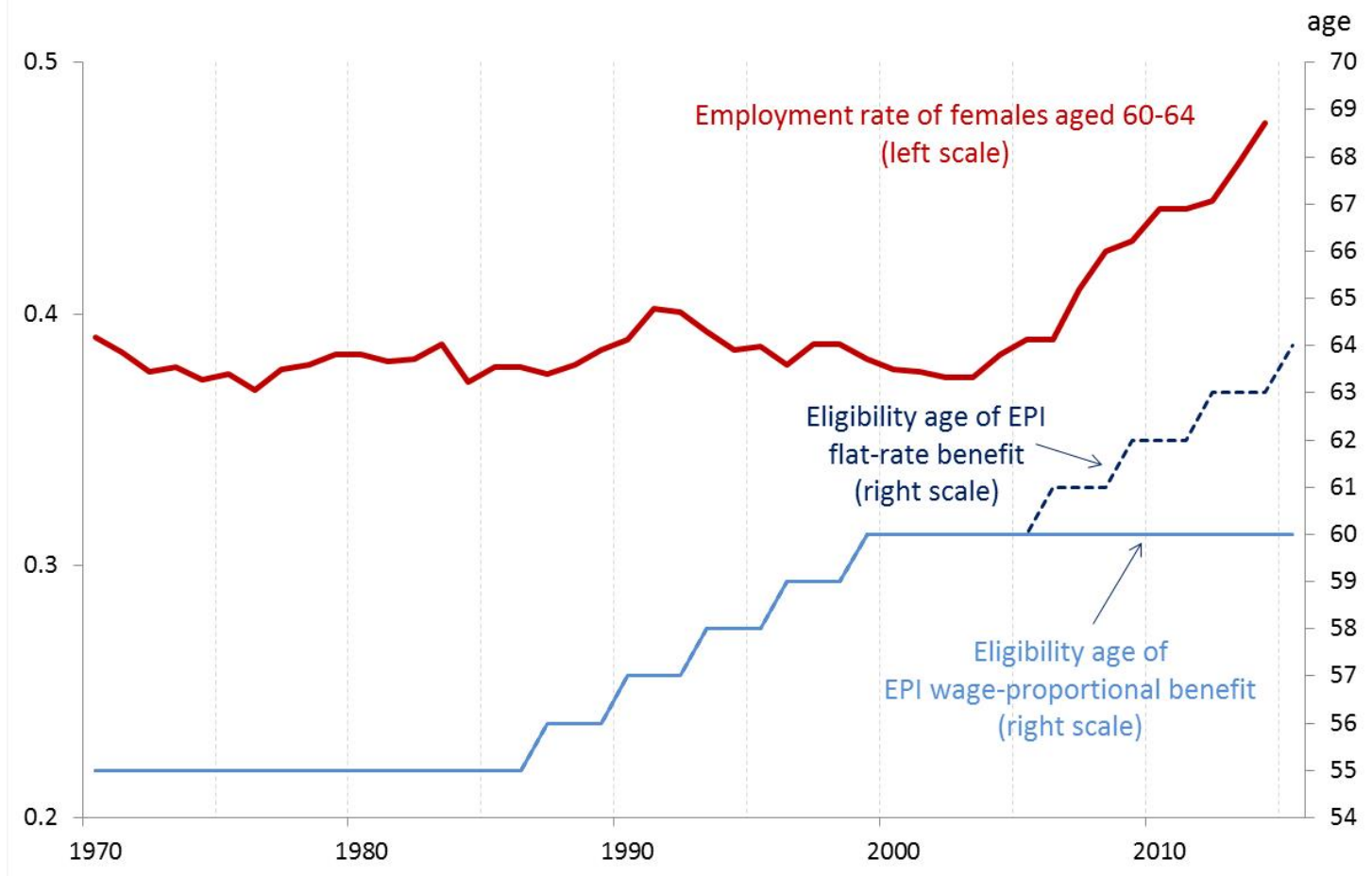


Figure 6. Decomposed changes in total employment for ages 60-64

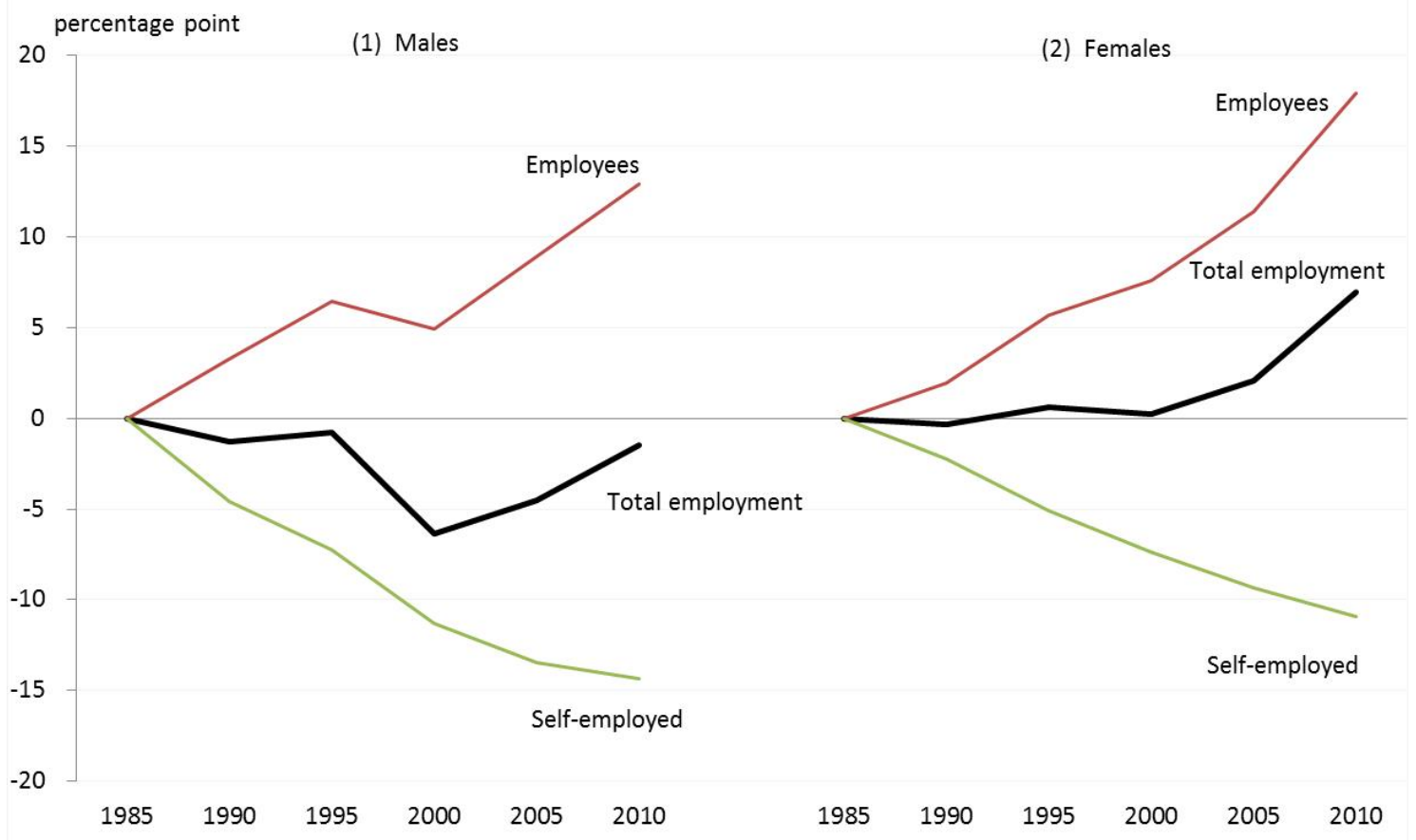

Figure 7. Proportion of part-time workers

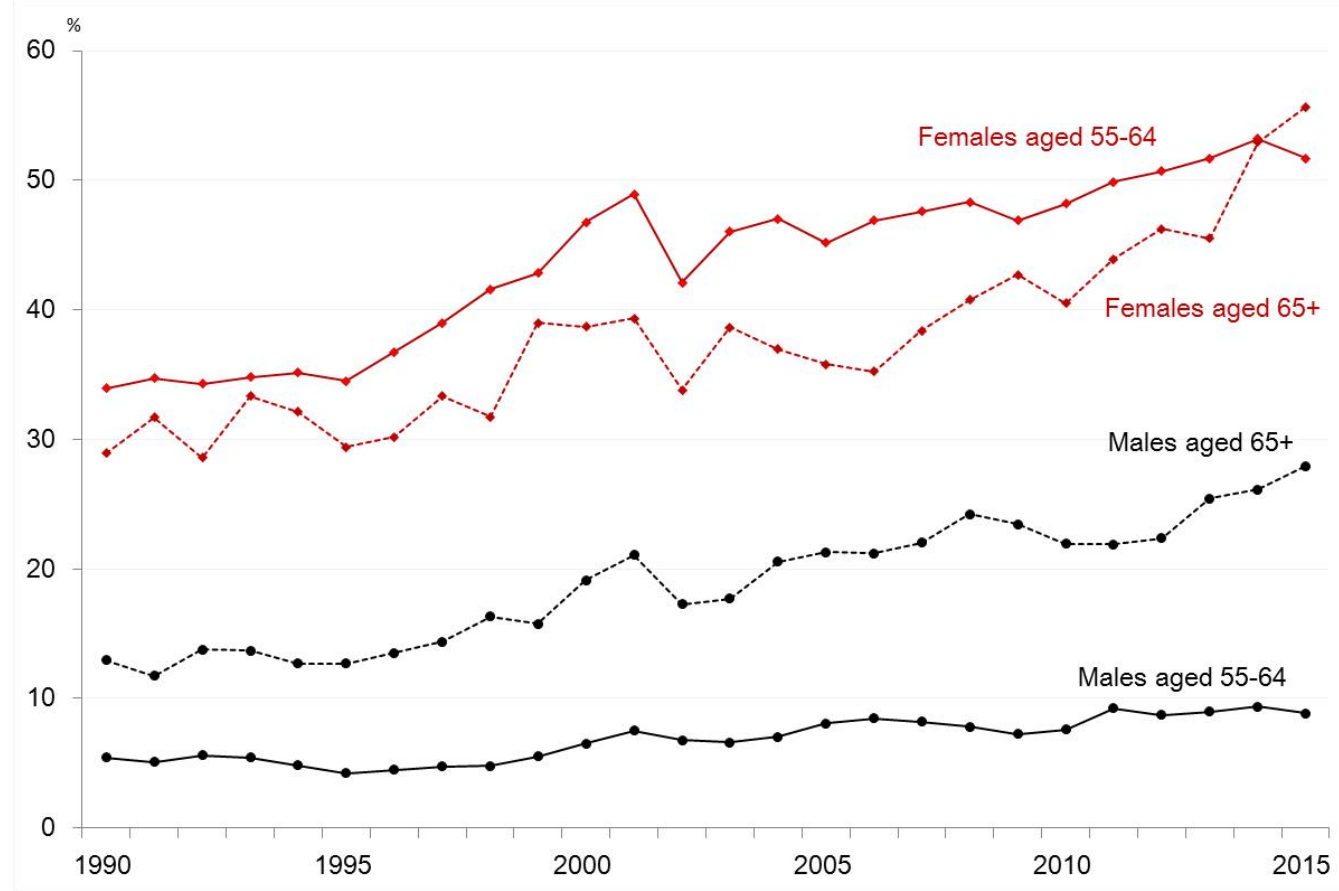


Figure 8. Proportion of college graduates and blue-collar workers

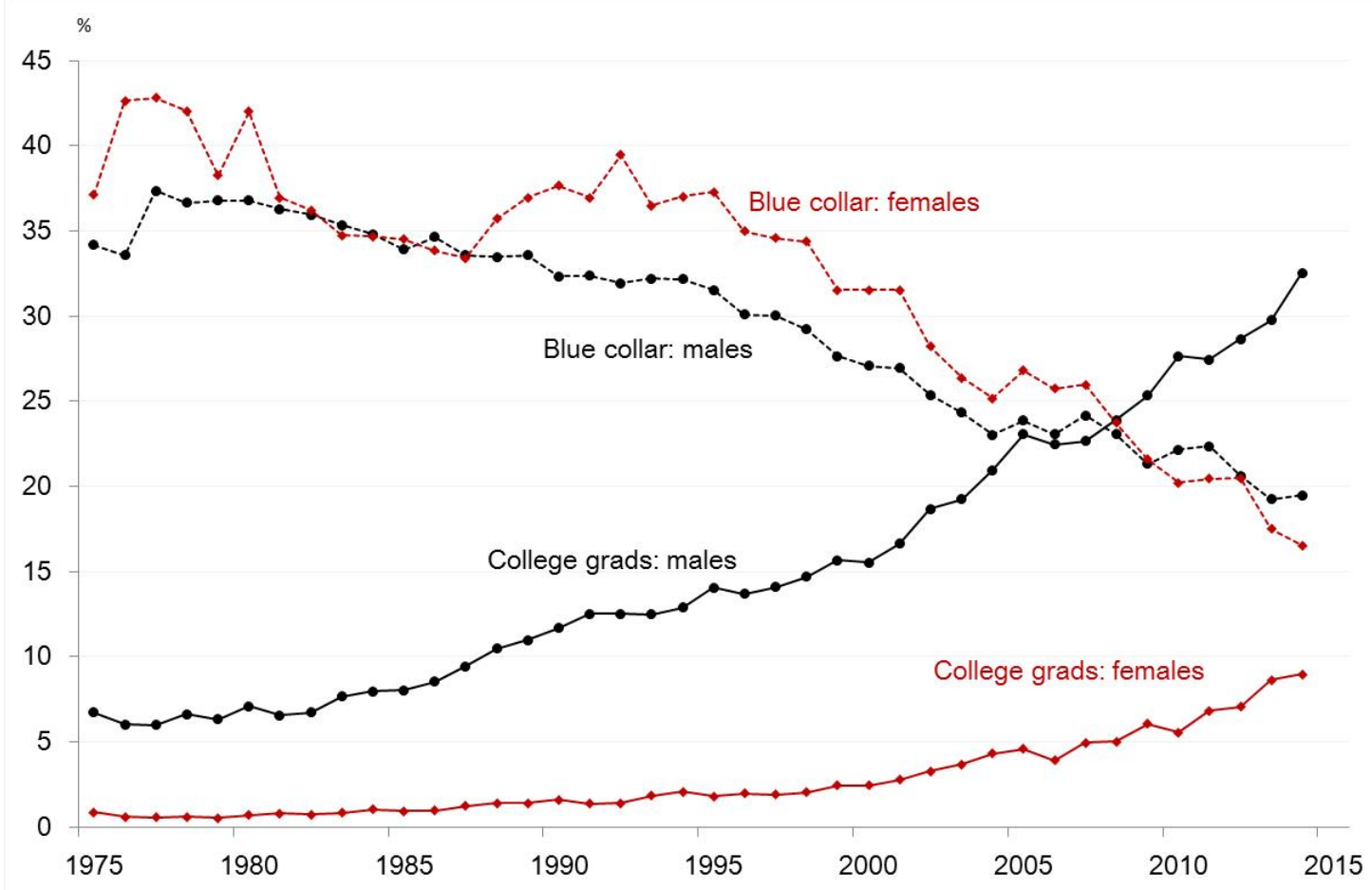

Figure 9. Life expectancy and mortality rates at age 60

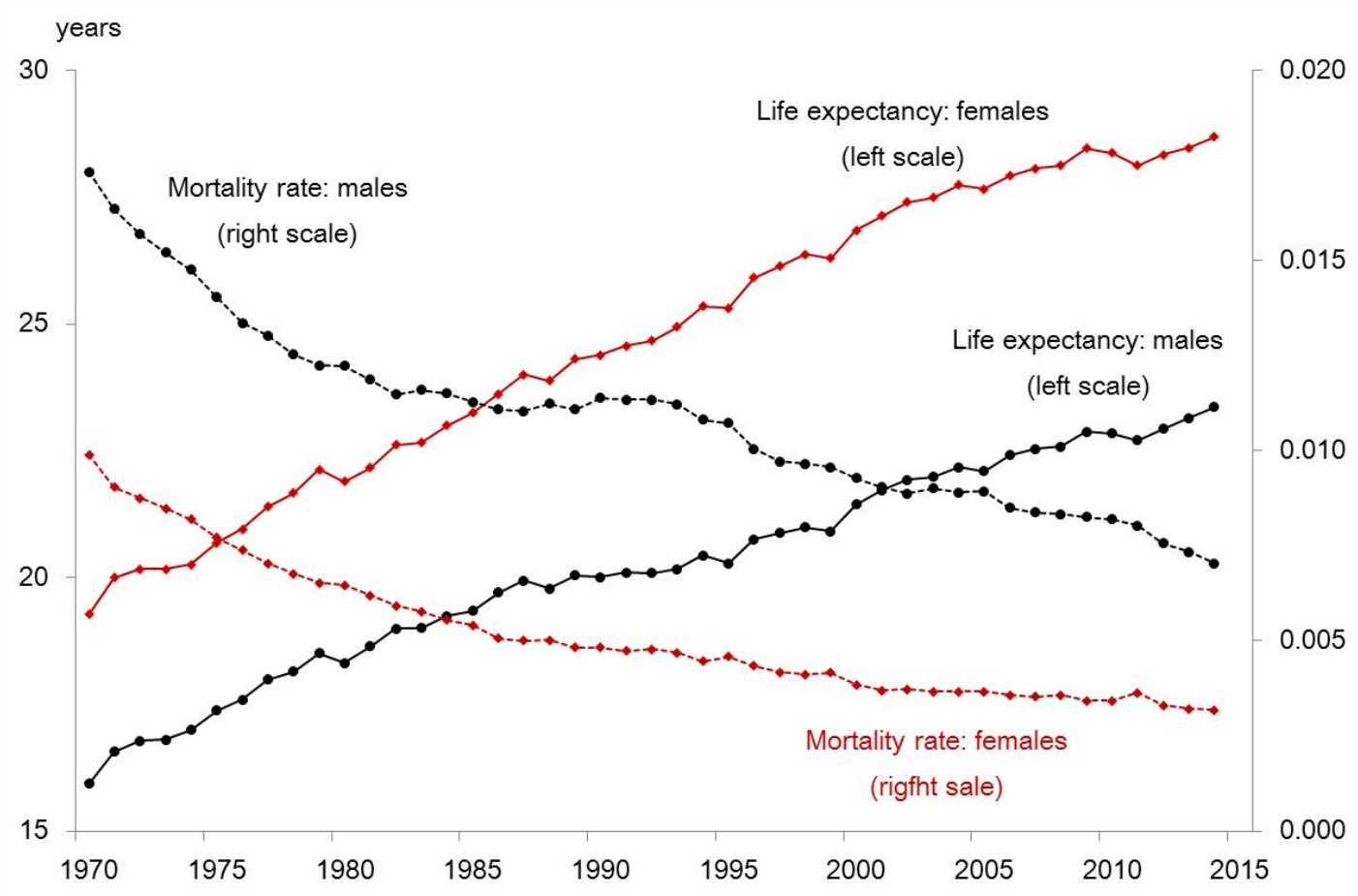


Figure 10. Mortality rate at age 60 and employment rate for ages 60-64

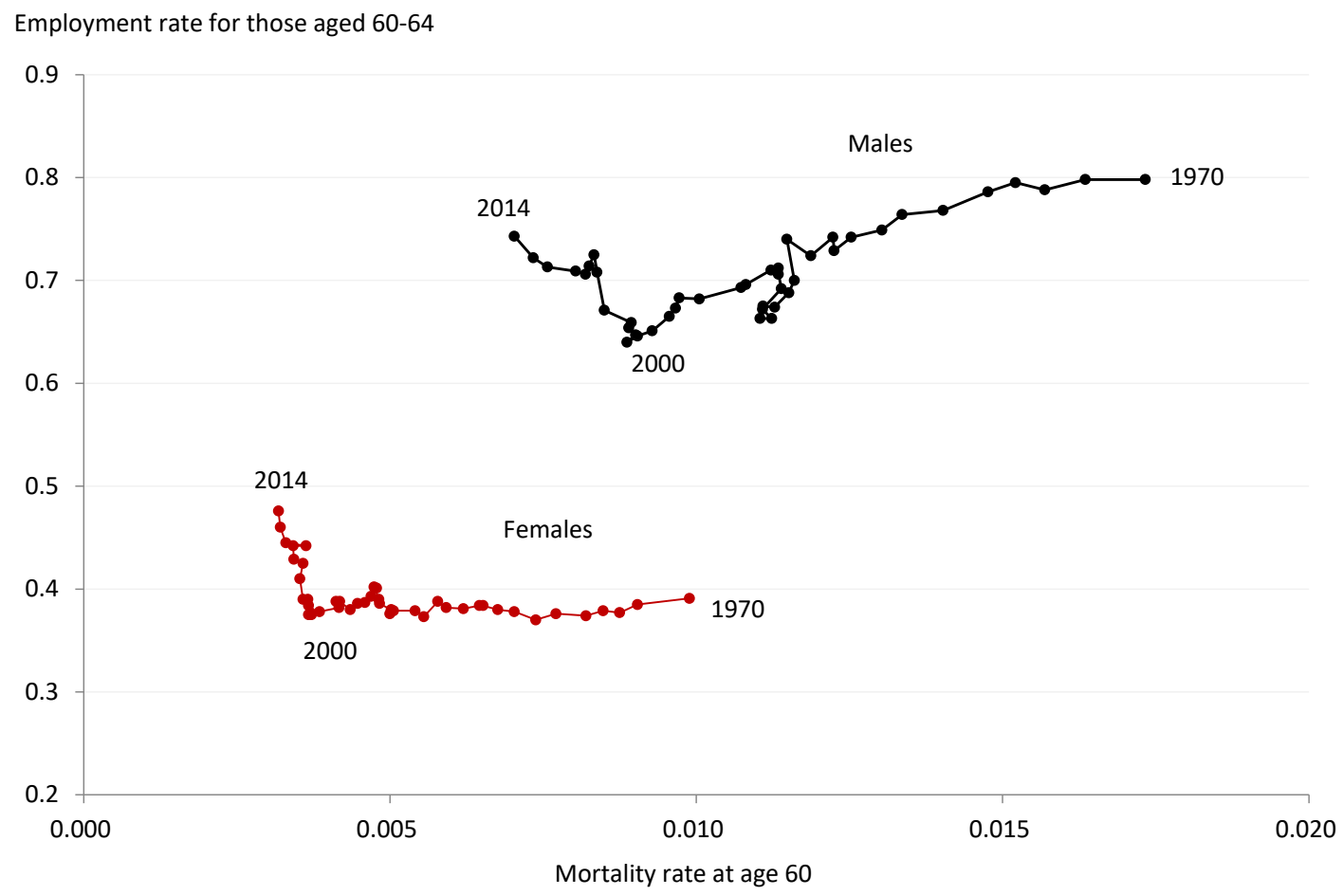

Figure 11a. Impact of social security reforms on OV: males aged 55-69

thousand yen, 2005 prices

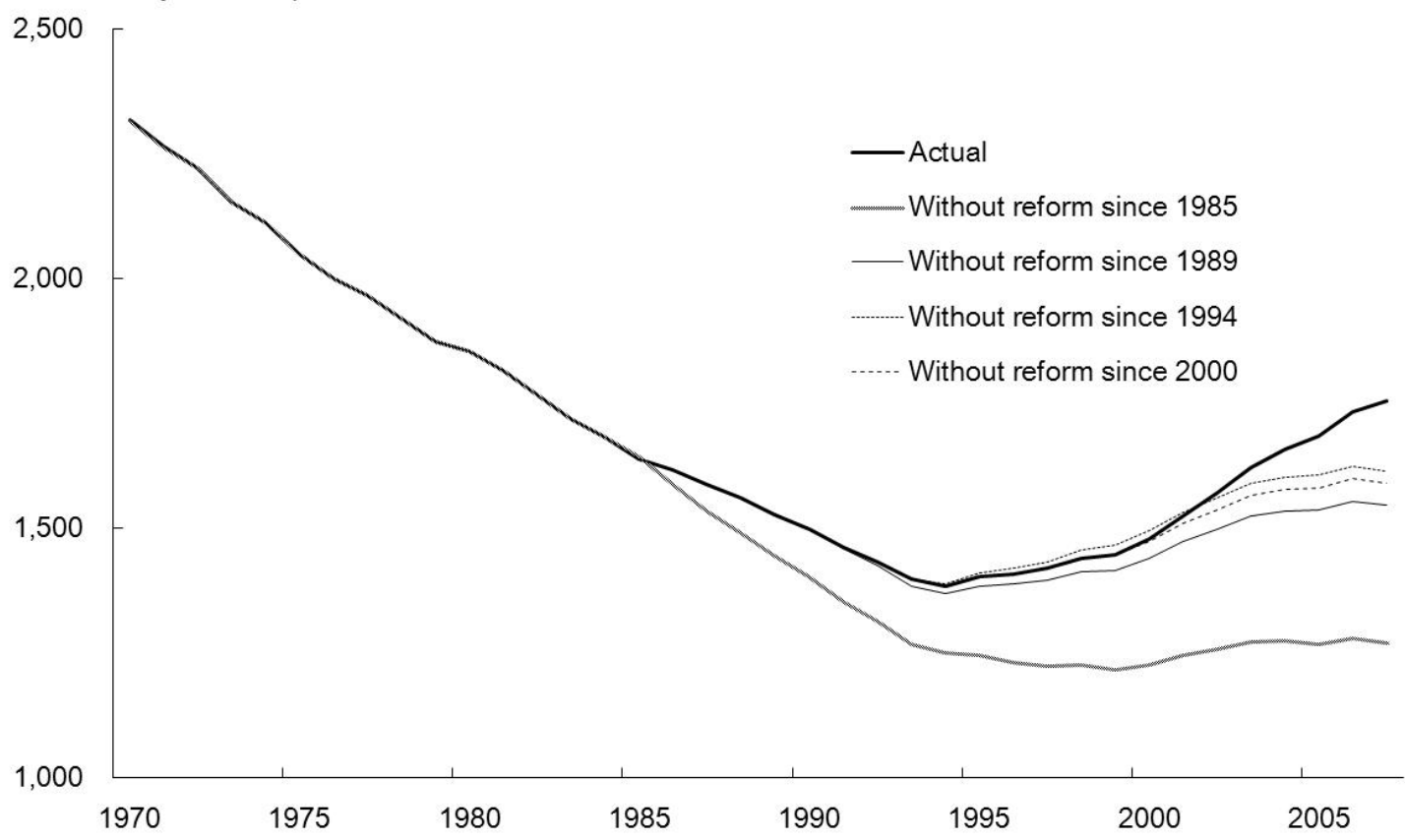

Source: Oshio, Oishi, and Shimizutani (2011) 
Figure 11b. Impact of social security reforms on OV: females aged 55-69

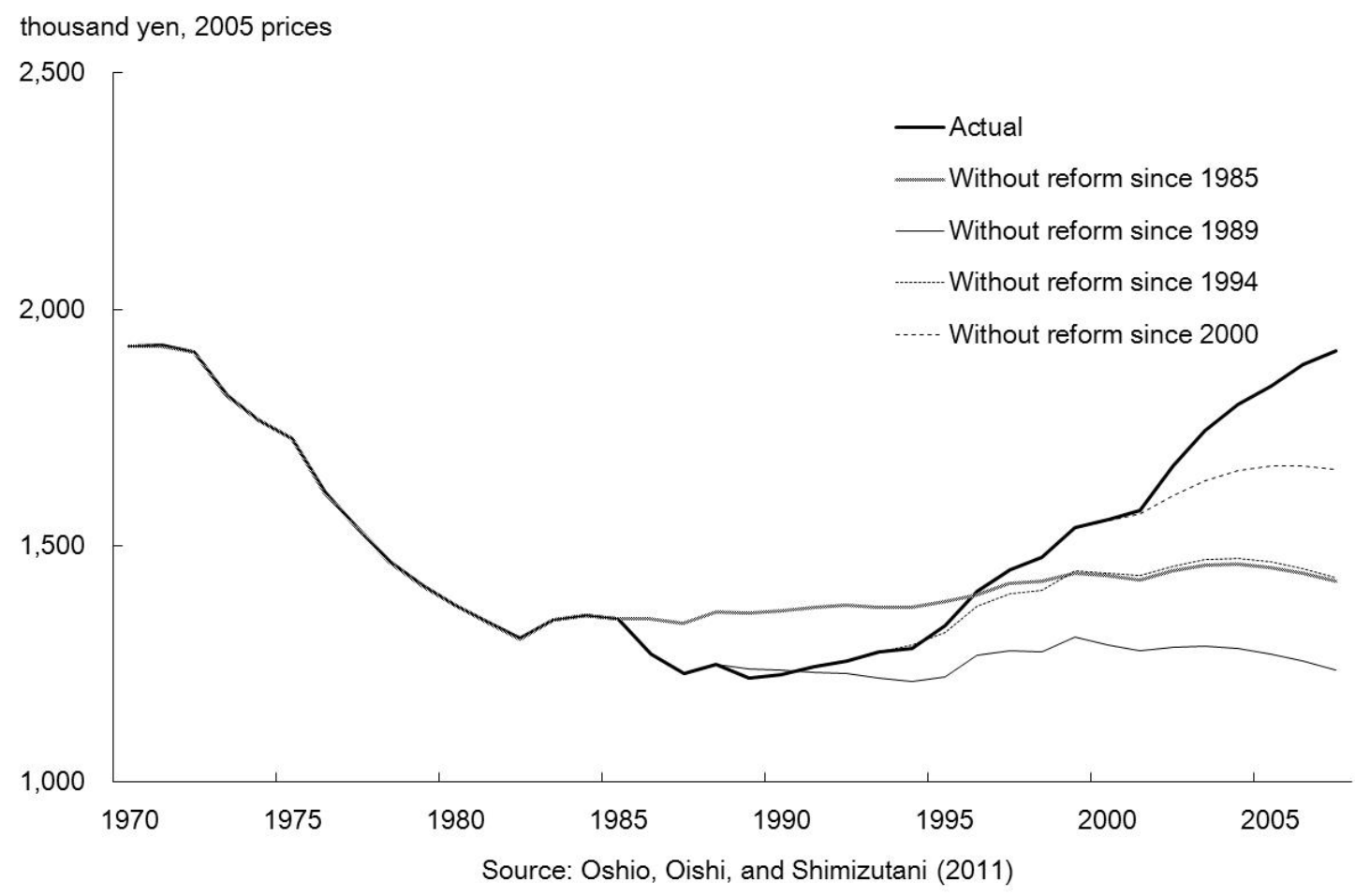

